\title{
Institutional Animal Care and Use Committee
}

National Cancer Institute

\section{Source}

National Cancer Institute. Institutional Animal Care and Use Committee. NCI Thesaurus. Code C19487.

A self-regulating entity mandated by federal law to be established at an institution that uses laboratory animals for research or instructional purposes to oversee and evaluate all aspects of the institution's animal use and care program. 